Trauma Surgery \& Acute Care Open

Department of Surgery, University of California San Francisco Fresno Center for Medical Education and Research, Fresno, California, USA

\section{Correspondence to} Dr Sammy Siada, Surgery, University of California San Francisco Fresno Center for Medical Education and Research, Fresno, CA 93721 USA; samsiada@gmail.com

Presented as a quickshot at the 70th Annual Meeting of the Southwestern Surgical Congress.

Received 11 April 2019 Revised 11 June 2019 Accepted 20 June 2019 (c) Author(s) (or their employer(s)) 2019. Re-use permitted under CC BY-NC. No commercial re-use. See rights and permissions. Published by BMJ.

To cite: Siada $\mathrm{S}$

Jeffcoach D, Dirks RC, et al.

Trauma Surg Acute Care Open 2019:4:e000324.

\title{
A predictive grading scale for acute cholecystitis
}

\author{
Sammy Siada, David Jeffcoach, Rachel C Dirks, Mary M Wolfe, Amy M Kwok, \\ Lawrence P Sue, James W Davis
}

ABSTRACT
Background Acute cholecystitis presents in a spectrum of severity, where acute disease may be complicated by severe inflammation, gangrene, and perforation. The goal of this study is to outline an evidence-based grading scale that predicts patient outcomes after laparoscopic cholecystectomy (LC).

Methods A retrospective review of all patients with a preoperative diagnosis of acute cholecystitis who underwent LC from August 2011 until June 2015 at a tertiary-level hospital was performed. Patients who underwent elective cholecystectomy, incidental cholecystectomy, a planned open cholecystectomy, had gallstone pancreatitis or choledocholithiasis, and those admitted to a non-surgical service were excluded. Severity of disease was obtained from operative and pathology reports, and patients were classified according to the following grading scale:

Grade l: symptomatic cholelithiasis.

Grade II: acute/chronic cholecystitis.

Grade III: gangrenous/necrotizing cholecystitis.

Grade IV: gallbladder perforation or abscess.

The groups were compared on age, gender, body mass index, severity of gallbladder disease, presence of preoperative systemic inflammatory response syndrome, hospital length of stay, length of operation, complications within 30 days, conversion to open rate, and cost of hospitalization.

Results During the study period, 1252 patients who underwent laparoscopic cholecystectomy were analyzed; 677 met inclusion criteria. The most common grade was grade 2 , which was present in $80 \%$ of patients, followed by grade 3 , which was found in $16 \%$ of patients.

Grade 4 cholecystitis occurred in $1.2 \%$ of patients and grade 1 occurred in $3.2 \%$ of patients. There were statistically significant increases in age, presence of preoperative systemic inflammatory response syndrome, hospital length of stay, conversion to open rate, cost of hospitalization, and length of operation with increased cholecystitis grade.

Conclusions The proposed grading scale is an accurate predictor of duration of operation, conversion to open rate, hospital length of stay, and cost of hospitalization.

Level of evidence III

Study type Prognostic

\section{BACKGROUND}

Acute cholecystitis is a common disease process that presents in a spectrum of severity where acute disease may be complicated by severe inflammation, gangrene, and perforation. There have been several attempts at developing an evidence-based grading scale to create a standardized system for characterizing disease severity. ${ }^{1-5}$
The first modern grading scale for acute cholecystitis was published in the Tokyo guidelines in 2007 and was further revised in 2013. ${ }^{2}$ The Tokyo guidelines classify acute cholecystitis into mild, moderate, and severe categories based on patient physiologic response including leukocytosis, local inflammatory response, and end-organ dysfunction. For example, severe cholecystitis was described as acute cholecystitis associated with end-organ dysfunction. The primary goal of the Tokyo guidelines was to establish diagnostic criteria for acute cholecystitis to guide clinical management. ${ }^{1-3}$

A recent German study also outlined a preoperative scoring system for acute cholecystitis based on preoperative patient risk factors including age, sex, American Society of Anesthesiologists class, gallbladder wall thickness, body mass index, white blood cell count, and C-reactive protein. They found that their scoring system correlated with length of stay, and length of operation, but was not associated with complication rate or conversion to open procedure rate. ${ }^{4}$

The American Association for the Surgery of Trauma (AAST) also introduced a grading scale for acute cholecystitis based on anatomic variables in their scoring system for emergency general surgery conditions. $^{5} 6$ This system uses clinical, imaging, operative, and pathologic criteria to quantify the severity of acute cholecystitis on a scale from 1 to 5 and, contrary to the Tokyo guidelines, excludes physiologic parameters. Grade 1 is acute cholecystitis and grade 2 is gangrenous or emphysematous cholecystitis. Grades 3-5 describe gallbladder perforation with local contamination, abscess or fistula, and generalized peritonitis, respectively.

Vera et al were the first to attempt to validate the AAST scoring system in $2017 .{ }^{7}$ They found that only $6 \%$ of patients fell into grades $3-5$ and no statistical differences in complications were identified between grades 1 and $2 .^{7}$ However, the length of stay, hospital readmission, and death all increased with increasing anatomic grade (3-5). Postoperative complications were not significantly associated with AAST grade, likely because most patients were clustered into the lower grades.

Given the heterogeneity and complexity of the aforementioned attempts at grading acute cholecystitis, the goal of this study is to outline a simplified, evidence-based grading scale for the acute care surgery (ACS) community that uses anatomic criteria to predict patient outcomes after laparoscopic cholecystectomy (LC). 


\section{METHODS}

A retrospective review was performed on patients undergoing cholecystectomy for acute cholecystitis from October 2011 through July 2015 at Community Regional Medical Center, a 650-bed tertiary-care and safety-net hospital in Fresno, California. The study was performed with the approval of the Institutional Review Board of Community Medical Centers and UCSF Fresno.

The study population included patients who were admitted from the emergency department to the ACS service with a diagnosis of acute cholecystitis who underwent laparoscopic cholecystectomy. Patients who underwent elective cholecystectomy, incidental cholecystectomy, a planned open cholecystectomy, had gallstone pancreatitis, choledocholithiasis, and those admitted to a non-surgical service were excluded from the study.

Data collected included the following: age, gender, presence of preoperative systemic inflammatory response syndrome (SIRS), length of operation, hospital length of stay, and cost of hospitalization (total cost to the hospital). SIRS was defined as presence of at least two of the following criteria present before surgery: temperature less than $36^{\circ} \mathrm{C}$ or greater than $38^{\circ} \mathrm{C}$, white blood cell count less than 4000 or greater than 12000 , heart rate greater than 90 beats per minute, and/or respiratory rate greater than 20 breaths per minute. ${ }^{8}$

Severity of disease was identified from operative and pathology records, and patients were classified according to the following scale:

Grade 1: symptomatic cholelithiasis (ie, no gallbladder inflammation).

Grade 2: acute cholecystitis.

Grade 3: gangrenous/necrotizing cholecystitis.

Grade 4: gallbladder perforation or abscess.

The primary outcomes of interest were overall length of stay, conversion to open cholecystectomy, rate of complications, and cost of hospitalization in relation to the various grades of the proposed scale. Cost data were obtained from hospital financial records and included the cost to the hospital for the patients' entire stay and operative procedure but did not include surgeon and anesthesia fees. The AAST grade was also determined for all patients.

Continuous data are presented as mean \pm SE of the mean and were analyzed using Kruskal-Wallis tests. Pairwise comparisons were done with post hoc Dunn-Bonferroni tests. Categorical data are reported as percentages and were compared with $\chi^{2}$ analysis. Statistics were performed using the Statistical Package for Social Sciences (SPSS V.23.0; IBM, Armonk, NY, USA) with significance attributed to a $\mathrm{p}$ value $<0.05$.

\section{RESULTS}

During the study period, 1252 patients with a preoperative diagnosis of acute cholecystitis, who underwent laparoscopic cholecystectomy, were seen at our institution. Of these, 575 patients who underwent elective cholecystectomy, incidental cholecystectomy, a planned open cholecystectomy, had gallstone pancreatitis, choledocholithiasis, and those admitted to a non-surgical service

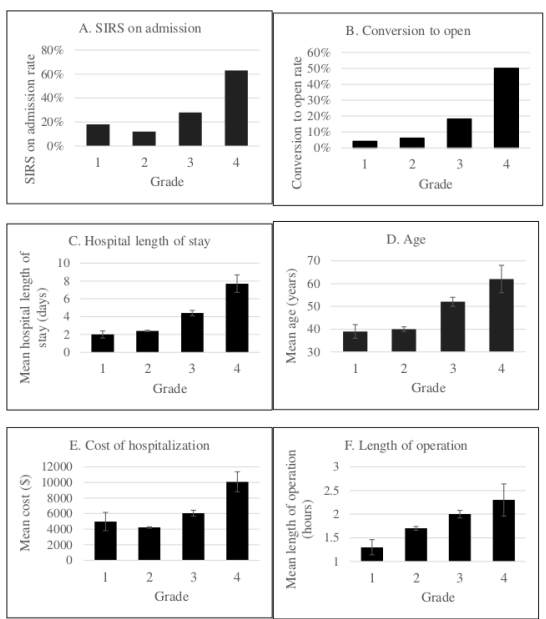

Figure 1 Bar graphs showing the positive correlation between cholecystitis grade and (A) SIRS at admission, (B) conversion to open rate, (C) hospital LOS, (D) age, (E) cost of hospitalization, and (F) length of operation. LOS, length of stay; SIRS, systemic inflammatory response syndrome.

were excluded from the study. The remaining 677 were included in analysis.

The most common grade was grade 2, which was present in $80 \%$ of patients, followed by grade 3, which was found in $16 \%$ of patients. Grade 4 cholecystitis occurred in $1.2 \%$ of patients and grade 1 occurred in $3.2 \%$ of patients. When applying the AAST grading scale to this patient population, $96 \%$ of patients fell into grade 1 or 2 . Only $1 \%$ of patients were grade 3 , one patient was grade 4 , and no patients were grade 5 .

There were statistically significant increases in age, presence of preoperative SIRS, hospital length of stay, conversion to open rate, cost of hospitalization, and length of operation with increased cholecystitis grade (table 1 and figure 1). Pairwise comparisons between cholecystitis grades for these variables are shown in table 2.

There was a strong association between male gender and gangrenous cholecystitis. While approximately one quarter of patients who had grade 1,2 , and 4 cholecystitis were male, $56 \%$ of patients with grade 3 cholecystitis were male, which is significantly higher than the other grades $(\mathrm{p}<0.001)$.

\section{DISCUSSION}

Grading cholecystitis by anatomic criteria can be useful for predicating outcomes after laparoscopic cholecystectomy, as morbidity is related to anatomic criteria. Several grading scales have been proposed, the most recent of which is the AAST grading scale; however, most of these scales are heavily skewed to lower grades. Therefore, the goal of this study was to create

\begin{tabular}{|c|c|c|c|c|c|c|c|}
\hline Grade & $\mathrm{N}$ & LOS (days) & Conversion to open & Age & SIRS at admission & Cost (US\$) & LOO (h) \\
\hline 1 & 22 & $2.0 \pm 0.4$ & $1(4 \%)$ & $39 \pm 3$ & $4(18 \%)$ & $4980 \pm 1172$ & $1.3 \pm 0.2$ \\
\hline 2 & 539 & $2.4 \pm 0.1$ & $33(6 \%)$ & $40 \pm 1$ & $64(12 \%)$ & $4206 \pm 86$ & $1.7 \pm 0.0$ \\
\hline 3 & 108 & $4.4 \pm 0.3$ & $19(18 \%)$ & $52 \pm 2$ & $30(28 \%)$ & $6057 \pm 371$ & $2.0 \pm 0.1$ \\
\hline 4 & 8 & $7.7 \pm 1.0$ & $4(50 \%)$ & $62 \pm 6$ & $5(63 \%)$ & $10078 \pm 1285$ & $2.3 \pm 0.4$ \\
\hline$P$ value & - & $<0.001$ & $<0.001$ & $<0.001$ & $<0.001$ & $<0.001$ & $<0.001$ \\
\hline
\end{tabular}

LOO, length of operation; LOS, length of stay; SIRS, systemic inflammatory response syndrome. 
Table 2 Comparisons of the grades of cholecystitis

\begin{tabular}{cllllll}
\hline & LOS & $\begin{array}{l}\text { Conversion } \\
\text { to open }\end{array}$ & Age & SIRS & Cost & L00 \\
\hline $\begin{array}{l}\text { Overall } p \\
\text { value }\end{array}$ & $<0.001$ & $<0.001$ & $<0.001$ & $<0.001$ & $<0.001$ & $<0.001$ \\
$\begin{array}{l}\text { Pairwise } p \\
\text { values }\end{array}$ & & & & & & \\
1 vs 2 & 0.15 & 1.00 & 1.00 & 0.33 & 1.00 & 0.043 \\
1 vs 3 & $<0.001$ & 0.19 & 0.003 & 0.43 & 0.004 & $<0.001$ \\
1 vs 4 & $<0.001$ & 0.011 & 0.009 & 0.032 & $<0.001$ & 0.005 \\
\hline vs 3 & $<0.001$ & $<0.001$ & $<0.001$ & $<0.001$ & $<0.001$ & $<0.001$ \\
\hline 2 vs 4 & $<0.001$ & 0.001 & 0.006 & 0.001 & $<0.001$ & 0.16 \\
\hline 3 vs 4 & 0.19 & 0.048 & 1.00 & 0.039 & 0.056 & 1.00 \\
\hline
\end{tabular}

LOO, length of operation; LOS, length of stay; SIRS, systemic inflammatory response syndrome.

a cholecystitis grading system that is predictive of outcomes and allows for a more equal distribution of patients.

The scale used in this study begins with patients having symptomatic cholelithiasis. Oftentimes, these patients may present with severe nausea and vomiting and inability to tolerate anything oral intake, but may or may not have the objective findings of cholecystitis such as leukocytosis, gallbladder wall thickening, or abnormal liver function tests. At operation, these patients often have a normal-appearing gallbladder. This population accounts for a significant number of patients who undergo urgent cholecystectomy and may represent a very early manifestation of cholecystitis caused by prolonged cystic duct obstruction. As a result, this is an important group to categorize on the spectrum of severity of cholecystitis and accounted for $3.2 \%$ of our patient population.

Gangrenous cholecystitis is a relatively uncommon diagnosis which accounts for substantial morbidity in this disease process. It is more common in elderly patients, diabetics, those who delay seeking medical care, ${ }^{9}$ and when compared with the other grades of cholecystitis, is significantly more common in men. Gangrenous cholecystitis occurs in up to $20 \%$ of patients with cholecystitis and accounts for $16 \%$ of patients in this cohort. ${ }^{9}$

When applying to the AAST grading scale to the patient population in this study, patients were heavily skewed to grades 1 and 2 , with less than $5 \%$ of patients in grades 3 and 4 , and no patients in grade 5 . This skew toward lower grades is likely related to the contemporary management of acute cholecystitis, where early recognition and treatment is the standard of care, which leads to prevention of more severe cholecystitis (eg, gangrene, abscess, perforation). ${ }^{10-14}$ Additionally, grades 3-5 of the AAST scale describe the various manifestations of gallbladder perforation, which is exceedingly uncommon, accounting for up to $2 \%$ of patients with cholecystitis and only $1.2 \%$ of patients in this study. ${ }^{9}$ This makes the AAST scale unreliable at predicting outcomes as it lumps the earlier manifestations of cholecystitis into one grade and splits the uncommon gallbladder perforation into three separate grades. As a result, the proposed grading scale in this study combined all perforations into one category, making it more accurate at predicting outcomes than the AAST scale.

Limitations of this study include its retrospective design, which may lead to selection and information bias. Additionally, this is a single-institution study, which may not completely reflect the general population. A prospective multicenter study could effectively validate this proposed grading scale.

The goal of this study was to outline a grading scale that reflects the spectrum of severity of acute cholecystitis in a way that can predict patient outcomes. The proposed grading scale demonstrates an increase in hospital length of stay, conversion to open, cost of hospitalization, and length of operation with increases in cholecystitis grade.

Contributors SS contributed to literature search, study design, data collection, data analysis, data interpretation, writing, and critical revision. DJ contributed to study design, data interpretation, and critical revision. RCD contributed to data collection, data analysis, data interpretation, and critical revision. JWD, MMW, LPS, and AMK contributed to study concept, data analysis, data interpretation, and critical revision

Funding The authors have not declared a specific grant for this research from any funding agency in the public, commercial or not-for-profit sectors.

Competing interests None declared.

Patient consent for publication Not required.

Ethics approval Institutional Review Board of Community Medical Centers and UCSF Fresno.

Provenance and peer review Not commissioned; externally peer reviewed.

Data availability statement All data relevant to the study are included in the article. No data are available.

Open access This is an open access article distributed in accordance with the Creative Commons Attribution Non Commercial (CC BY-NC 4.0) license, which permits others to distribute, remix, adapt, build upon this work non-commercially, and license their derivative works on different terms, provided the original work is properly cited, appropriate credit is given, any changes made indicated, and the use is non-commercial. See: http://creativecommons.org/licenses/by-nc/4.0/.

\section{REFERENCES}

1. Hirota M, Takada T, Kawarada Y, Nimura Y, Miura F, Hirata K, Mayumi T, Yoshida M, Strasberg S, Pitt H, et al. Diagnostic criteria and severity assessment of acute cholecystitis: Tokyo Guidelines. J Hepatobiliary Pancreat Surg 2007;14:78-82.

2. Yokoe M, Takada T, Strasberg SM, Solomkin JS, Mayumi T, Gomi H, Pitt HA, Garden OJ, Kiriyama S, Hata J, et al. TG13 diagnostic criteria and severity grading of acute cholecystitis (with videos). J Hepatobiliary Pancreat Sci 2013;20:35-46.

3. Yokoe M, Hata J, Takada T, Strasberg SM, Asbun HJ, Wakabayashi G, Kozaka K, Endo I, Deziel DJ, Miura F, et al. Tokyo guidelines 2018: diagnostic criteria and severity grading of acute cholecystitis (with videos). J Hepatobiliary Pancreat Sci 2018:25:41-54

4. Ambe $P C$, Papadakis $M$, Zirngibl H. A proposal for a preoperative clinical scoring system for acute cholecystitis. J Surg Res 2016;200:473-9.

5. Shafi S, Aboutanos M, Brown CV-R, Ciesla D, Cohen MJ, Crandall ML, Inaba K, Miller PR, Mowery NT, . American Association for the Surgery of Trauma Committee on Patient Assessment and Outcomes. Measuring anatomic severity of disease in emergency general surgery. J Trauma Acute Care Surg 2014;76:884-7.

6. Tominaga GT, Staudenmayer KL, Shafi S, Schuster KM, Savage SA, Ross S, Muskat P, Mowery NT, Miller P, Inaba K, et al. The American Association for the Surgery of Trauma grading scale for 16 emergency general surgery conditions: diseasespecific criteria characterizing anatomic severity grading. J Trauma Acute Care Surg 2016;81:593-602

7. Vera K, Pei KY, Schuster KM, Davis KA. Validation of a new American Association for the Surgery of Trauma (AAST) anatomic severity grading system for acute cholecystitis. J Trauma Acute Care Surg 2018;84:650-4.

8. Bone RC, Balk RA, Cerra FB, Dellinger RP, Fein AM, Knaus WA, Schein RM, Sibbald WJ. Definitions for sepsis and organ failure and guidelines for the use of innovative therapies in sepsis. The ACCP/SCCM Consensus Conference Committee. American College of Chest Physicians/Society of Critical Care Medicine. Chest 1992:101:1644-55

9. Reiss R, Nudelman I, Gutman C, Deutsch AA. Changing trends in surgery for acute cholecystitis. World J Surg 1990;14:567-70.

10. Gurusamy KS, Samraj K. Early versus delayed laparoscopic cholecystectomy for acute cholecystitis. Cochrane Database Syst Rev 2006.

11. McArthur P, Cuschieri A, Sells RA, Shields R. Controlled clinical trial comparing early with interval cholecystectomy for acute cholecystitis. Br J Surg 1975;62:850-2.

12. Brooks KR, Scarborough JE, Vaslef SN, Shapiro ML. No need to wait: an analysis of the timing of cholecystectomy during admission for acute cholecystitis using the American College of Surgeons National Surgical Quality Improvement Program database. J Trauma Acute Care Surg 2013;74:167-73-73.

13. Gutt CN, Encke J, Köninger J, Harnoss J-C, Weigand K, Kipfmüller K, Schunter O, Götze T, Golling MT, Menges M, et al. Acute cholecystitis: early versus delayed cholecystectomy, a multicenter randomized trial (ACDC study, NCT00447304). Ann Surg 2013;258:385-93.

14. Gurusamy KS, Davidson C, Gluud C, Davidson BR. Early versus delayed laparoscopic cholecystectomy for people with acute cholecystitis. Cochrane Database Syst Rev 2013(6):CD005440 